\title{
Effect of Chronic Intracerebroventricular Infusion of Corticotropin-Releasing Factor on Circadian Corticosterone Rhythm in the Rat
}

\author{
Ken MIYANAGA, Susumu MIYABO and EIIChi OOYA \\ Department of Internal Medicine, Fukui Medical School, \\ Fukui 910-11, Japan,
}

\begin{abstract}
The effects of chronic (14 day) intracerebroventricular infusion of various amounts of ovine corticotropin-releasing factor (oCRF) on the circadian blood corticosterone rhythm in male rats were examined. Control (saline-infused) rats showed distinct blood corticosterone rhythms over $48 \mathrm{~h}$ with nadirs at $0900 \mathrm{~h}$ and peaks at $2100 \mathrm{~h}$ on days $6-7$ and $13-14$. oCRF at $3 \mathrm{pmol} / \mathrm{h} \mathrm{did}$ not affect the circadian corticosterone rhythm on these days. When oCRF was infused at a rate of $12 \mathrm{pmol} / \mathrm{h}$, blood corticosterone was increased throughout the $48 \mathrm{~h}$ periods. A significant circadian rhythm remained at days $6-7$, but continuous infusion for an additional 7 days disrupted the rhythm. Higher doses of oCRF ( 48 and $240 \mathrm{pmol} / \mathrm{h}$ ) obliterated the rhythm during both periods; the disruption was characterized by an increase in corticosterone during the lights-on period without a substantial change in the evening maximum. Thus, the blood corticosterone concentration was eventually confined within a narrow range, not exceeding the normal circadian peak, over a wide dose range of centrally administered CRF. Significant effects of oCRF on body and adrenal weight were observed only at the two highest doses used. These findings may provide some insight into the state of the hypothalamic-pituitary-adrenal axis in animals exposed to chronic stress and in patients with depression.
\end{abstract}

Recently extensive study has been conducted on the regulation and functional properties of neurohormones in the search for a possible biologic basis of major depression. Gold et al. (1988a) have cited striking similarities between behavioral and

\footnotetext{
Received February 23, 1989

Correspondence: KEN MIYANAGA, Department of Internal Medicine, Fukui Medical School, Matsuoka-Cho, Yoshida-Gun, Fukui Prefecture, 910-11, Japan. (Telephone : 0776-613111 (Japan) Ext. 2304)
}

physiologic changes during the adaptive phase to various stressors and the depression syndrome. Among them, hyperactivity of the hypothalamic-pituitary-adrenal (HPA) system is one of the most consistent findings, and sustained hypersecretion of corticotropin-releasing factor (CRF) has been implicated as a causative factor (Gold et al., 1986b; Taylor and Fishman, 1988).

In contrast to numerous reports on acute CRF administration, there are very few reports on the effects of chronic, continuous CRF administration on pituitary- 
adrenocortical activity (Rivier and Vale, 1985; Silberg and Funder, 1988; Gertz et al., 1987), and virtually no studies have dealt with circadian variation, which is a major driving mechanism of the system in addition to stress. This prompted us to examine the circadian blood corticosterone profile in rats, which received a continuous intracerebroventricular (icv) infusion of oCRF for 14 days. The icv route was chosen because (1) with the exception of the report of Cunningham et al. (1988), there has been no study on chronic icv infusion of CRF and (2) the icv, but not peripheral, administration of CRF produces a variety of physiological as well as behavioral changes similar to those seen ir experimental animals subjected to stressful situations (Sutton et al., 1982; Kalin, 1983; Lenz et al., 1987).

\section{Materials and Methods}

Adult male Wistar rats $(250-300 \mathrm{~g})$ were used for the study. They were fed rat chow and water ad libitum, and housed under a $12 \mathrm{~h}$ light/ $12 \mathrm{~h}$ dark cycle (lights on at $0900 \mathrm{~h})$. After one week adaptation, the pre-CRF (days -1 and 0 ) blood corticosterone rhythm was examined by repeated blood sampling $(10 \mu \mathrm{l})$ at 4 -h intervals over $48 \mathrm{~h}$ from a small incision at the tail tip, as described previously (Miyabo et al., 1981). This procedure has been proven not to disturb the endogenous circadian rhythm of plasma corticosterone (Homma and Horoshige, 1979). On the following day (day 1), a 21-gauge stainless steel cannula was inserted stereotaxically into the third cerebral ventricle of the animal ( $2 \mathrm{~mm}$ caudal to the bregma in the midline, 8 $\mathrm{mm}$ deep) (Albe-Fessard et al., 1966), under pentobarbital anesthesia, and fixed to the skull with dental cement. The intracerebroventricular (icv) infusion of oCRF (Peptide Institute, Osaka, Japan) was made by means of an Alzet osmotic minipump (mode1 2001, Alza Corp., Palo Alto, CA., pumping rate, $1.0 \mu 1 / \mathrm{h}$ ) which was filled with oCRF dissolved in physiological saline, connected to the cannula, and implanted under the dorsal skin. The concentrations of infusate were adjusted to deliver oCRF at rates of 3 $(\mathrm{n}=7), 12(\mathrm{n}=6)$, and $48(\mathrm{n}=5) \mathrm{pmol} / \mathrm{h}$. Control animals $(n=7)$ received an icv infusion of saline alone. On days $6-7$, the $48 \mathrm{~h}$ blood corticosterone pattern was determined as above and the minipumps were replaced. On days 13-14 the final blood corticosterone profile was obtained. In a separate experiment $(n=6)$, the dose of oCRF was increased to $240 \mathrm{pmol} / \mathrm{h}$ and blood samples were taken at $0900 \mathrm{~h}$ (the nadir) and $2100 \mathrm{~h}$ (the peak) on days 6-7 and 13-14. In these rats, locomotor activity was continuously monitored during the last 3 days using Animex III-DSE (Shimazu, Kyoto, Japan) as described previously (Miyabo et al., 1985). The stability of oCRF was confirmed by bioassaying the outflow fluid from the minipumps in a separate group of animals on day 7 . Body weight was measured before infusion and on days 7 and 14 of the infusion. Before sacrifice on day 14, the infusion site was verified by injecting $5 \mu \mathrm{l}$ of indigocarmine through the cannula. The pituitary and adrenals were weighed to the nearest $0.1 \mathrm{mg}$. Blood corticosterone was determined by radioimmunoassay, as described previously (Miyabo et al., 1981). The grouped corticosterone data were analyzed by analysis of variance (ANOVA) on variation over time. The Newman Keuls (N-K) test was used for peak-trough corticosterone difference and to compare body and organ weight.

\section{Results}

Before icv oCRF infusion, every rat showed a distinct circadian corticosterone rhythm with a nadir at $0900 \mathrm{~h}$ and a peak at $2100 \mathrm{~h}$ (data not shown). The icv infusion of saline (control) or $3 \mathrm{pmol} / \mathrm{h}$ oCRF did not affect the corticosterone rhythm at days 6-7 or 13-14. Although the peak concentration of the group receiving $3 \mathrm{pmol} /$ $h$ tended to be lower than that of the control, the difference was not significant. In contrast, oCRF at $12 \mathrm{pmol} / \mathrm{h}$ for 7 days increased plasma corticosterone throughout the $48 \mathrm{~h}$ measurement interval, the rise being particularly evident during the lightson period $(\mathrm{P}<0.01$ vs controls $)$. The increase in the evening peak was not signi- 


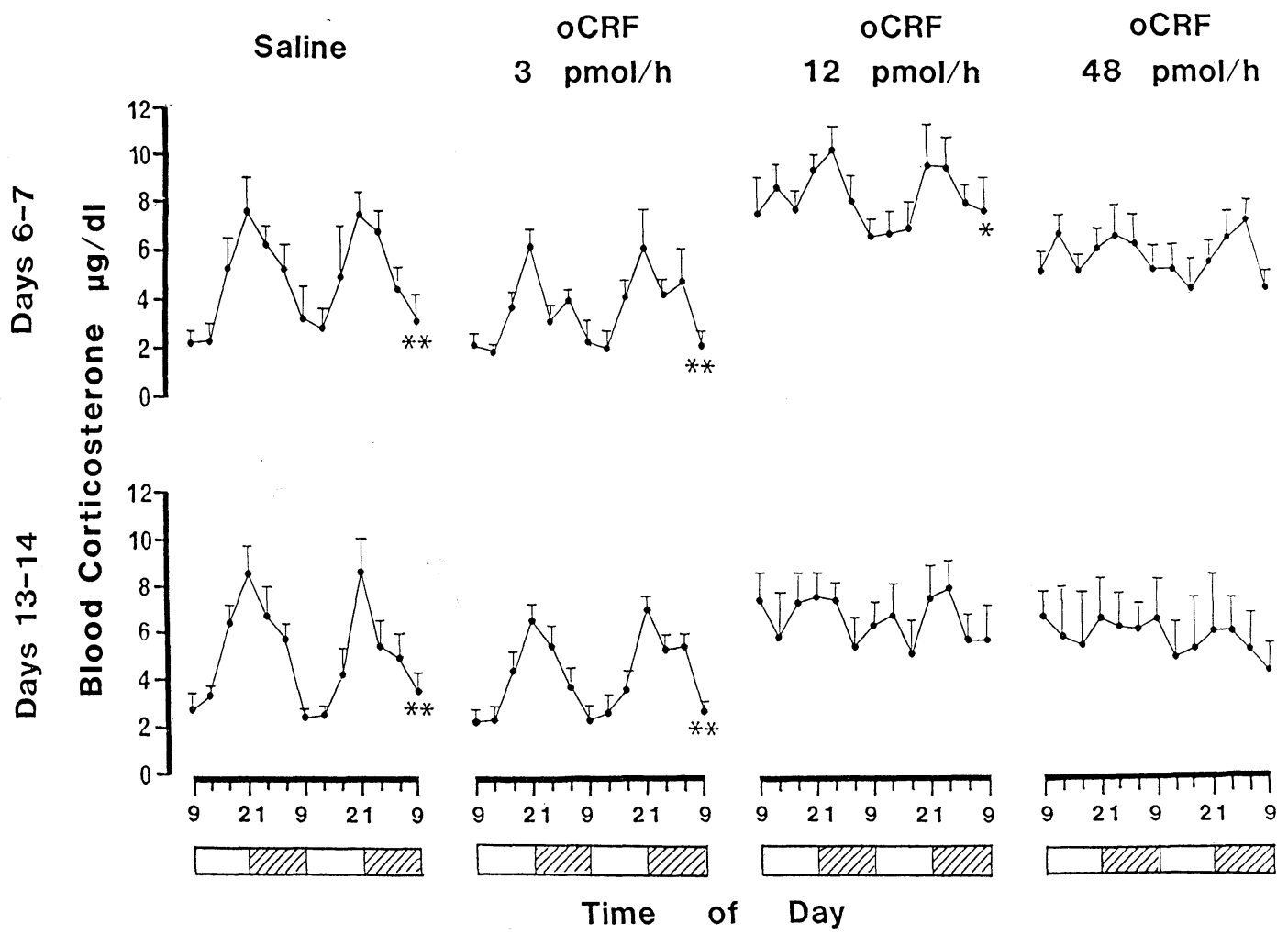

Fig. 1. Circadian pattern of blood corticosterone (mean \pm SEM) in rats treated with icv oCRF for 14 days. Light and dark periods are shown by open and hatched bars below the figure. Presence of circadian rhythm is indicated by $*(\mathrm{p}<0.05)$ and $* *(\mathrm{p}<0.01)$, as calculated by ANOVA and N-K test for grouped data.

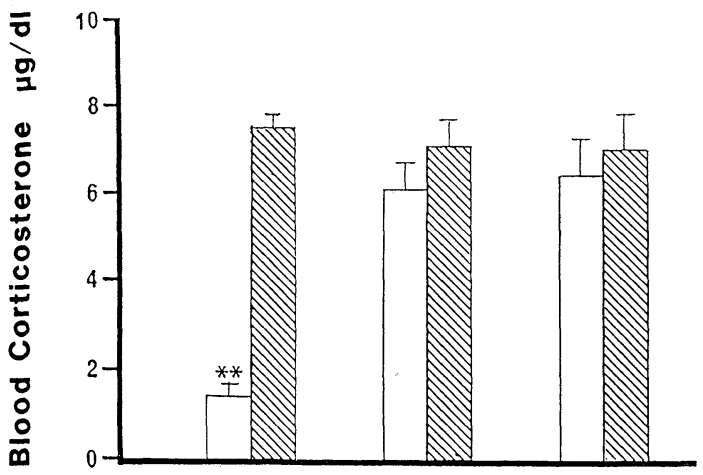

Days -1-0 Days 6-7 Days 13-14

Fig. 2. Blood corticosterone concentration (mean \pm SEM) in rats treated with $240 \mathrm{pmol} /$ h oCRF for 14 days. Open bars=corticosterone at $0900 \mathrm{~h}$; hatched bars $=$ corticosterone at $2100 \mathrm{~h}$. **indicates $\mathrm{p}<0.01$ in the $\mathrm{N}-\mathrm{K}$ test. ficant, but the circadian corticosterone rhythm was preserved $(\mathrm{P}<0.05)$. When the same dose of oCRF was continued for a further 7 day period, the circadian corticosterone rhythm was lost. A larger dose of oCRF $(48 \mathrm{pmol} / \mathrm{h})$ abolished the corticosterone rhythm at both days 6-7 and days 13-14. The disruption of the corticosterone rhythm was mainly due to an increase in the trough concentration without a significant increase in the peak (Fig. 1). This finding was supported by the experiment with $240 \mathrm{pmol} /$ $\mathrm{h}$ oCRF. The morning concentration rose as high as the evening concentration, whereas the latter remained unaltered before and after oCRF (Fig. 2). The distinct circadian locomotor rhythm was observed in 
Table 1. Effects of icv administration of oCRF for 14 days on body and organ weight

\begin{tabular}{|c|c|c|c|c|c|c|}
\hline \multirow[b]{2}{*}{ Treatment } & \multirow[b]{2}{*}{$\mathrm{n}$} & \multicolumn{3}{|c|}{ Body weight, g } & \multirow{2}{*}{$\begin{array}{c}\text { Pituitary } \\
\text { weight } \\
\mathrm{mg} / 100 \mathrm{~g} \mathrm{BW}\end{array}$} & \multirow{2}{*}{$\begin{array}{l}\text { Adrenal } \\
\text { weight } \\
\mathrm{mg} / 100 \mathrm{~g} \mathrm{BW}\end{array}$} \\
\hline & & Day 0 & Day 7 & Day 14 & & \\
\hline Control, saline & 7 & $288.7 \pm 7.8$ & $311.4 \pm 7.3$ & $333.0 \pm 9.2$ & $2.7 \pm 0.1$ & $12.1 \pm 0.8$ \\
\hline $3 \mathrm{pmol} / \mathrm{h}$ oCRF & 7 & $290.7 \pm 4.9$ & $319.0 \pm 4.1$ & $331.0 \pm 9.3$ & $2.8 \pm 0.1$ & $13.7 \pm 0.7$ \\
\hline $12 \mathrm{pmol} / \mathrm{h}$ oCRF & 6 & $275.5 \pm 5.6$ & $288.6 \pm 5.4$ & $319.5 \pm 5.5$ & $2.6 \pm 0.1$ & $13.7 \pm 0.6$ \\
\hline $48 \mathrm{pmol} / \mathrm{h}$ oCRF & 5 & $299.3 \pm 7.6$ & $287.6 \pm 10.9$ & $267.0 \pm 25.6^{*}$ & $2.7 \pm 0.1$ & $17.4 \pm 2.5^{* *}$ \\
\hline $240 \mathrm{pmol} / \mathrm{h}$ oCRF & 6 & $286.7 \pm 6.3$ & $285.8 \pm 6.8^{*}$ & $218.8 \pm 6.7 * *$ & $2.5 \pm 0.1$ & $17.2 \pm 0.9 * *$ \\
\hline
\end{tabular}

Data are presented as means \pm SEM. $* \mathrm{P}<0.05 ; * * \mathrm{P}<0.01 . \quad \mathrm{BW}=$ body weight.

every CRF-treated rat (data not shown).

The effects of centrally administered oCRF on body and organ weight are shown in Table 1. A significant suppression of body weight gain was noted in rats treated with $48 \mathrm{pmol} / \mathrm{h}$ oCRF, while $240 \mathrm{pmol} / \mathrm{h}$ oCRF caused a marked weight loss. The relative pituitary weight did not change, while the relative adrenal weight was increased only with 48 and $240 \mathrm{pmol} / \mathrm{h}$ oCRF.

\section{Discussion}

In this study, with the exception of the lowest dose, chronic icv infusion of oCRF increased the morning corticosterone concentration. In adrenalectomized rats implanted with a sc corticosterone pellet, which provides a constant corticosterone signal, bilateral lesions of the suprachiasmatic nuclei ( $\mathrm{SCN}$ ) eliminate the evening rise in plasma ACTH (Cascio et al., 1987). Together with a very low morning concentration of $\mathrm{ACTH}$ and corticosterone in intact rats, it is likely that under basal conditions the HPA axis is "turned off" in the morning (which may represent only constitutive secretion) and the drive from the SCN to $\mathrm{CRF}$ neurons in the paraventricular nuclei $(\mathrm{PVN})$ is supplied only in the evening (Dallman et al. 1987a). Thus, it is reasonable to suppose that chronic CRF above a certain dose increased the trough corticos- terone. Indeed, Gertz et al., (1987) noticed that during a 52-day sc infusion of rCRF $(94.4 \mathrm{pmol} / \mathrm{h})$, plasma corticosterone at 0800-0900 h was consistently increased to a mean of $7.5 \pm 0.99 \mu \mathrm{g} / \mathrm{dl}$ (vs $1.14 \pm 0.05 \mu \mathrm{g}$ ) $\mathrm{dl}$ in the control rats), which was also within the circadian excursion of plasma corticosterone in normal rats reported elsewhere (Dallman et al., 1987a). The paper by Rivier and Vale (1985) did not specify the time of sacrifice, but judging from the amount of ACTH and corticosterone in their control rats $(51.3 \pm 2.6 \mathrm{pg} / \mathrm{ml}$ and $1.78 \pm 0.32 \mu \mathrm{g} / \mathrm{dl}$, respectively), their values probably represent a trough or near-trough concentration. After 7-day exposure to 75 $\mathrm{pmol} / \mathrm{h}$ sc oCRF, plasma corticosterone rose to $2.28 \pm 0.74 \mu \mathrm{g} / \mathrm{dl}$ (within the normal circadian range). After $750 \mathrm{pmol} / \mathrm{h}$ oCRF for 7 days, however, the corticosterone value increased to $12.28 \pm 1.53 \mu \mathrm{g} / \mathrm{dl}$, which exceeds the circadian peak concentration in their intact rats $(6.3 \mu \mathrm{g} / \mathrm{dl})$. The latter dose, however, is extremely large and caused a further increase in plasma ACTH in adrenalectomized rats.

It is intriguing that increased blood corticosterone with a persistent circadian rhythm was observed only transiently when oCRF was infused at $12 \mathrm{pmol} / \mathrm{h}$ for 7 days. Exposure to oCRF for a longer period or at larger doses disrupted the corticosterone rhythm, but the concentration did not exceed the circadian peak observed in the saline-treated controls. Silberberg and 
Funder (1988) reported that plasma ACTH, $\beta$-endorphin, and corticosterone are not increased after a $72 \mathrm{~h}$ sc infusion of $\mathrm{rCRF}$ at rates up to $68 \mathrm{pmol} / \mathrm{h}$. Although the time of blood collection was not specified, the rather high plasma hormone concentration in their control group suggest that the animals were dealt with in the evening.

Although controversy remains, there seems to be no intrinsic circadian change in pituitary responsiveness to CRF (Akana et al., 1986). Dallman et al. (1985) infused $\mathrm{rCRF}$ at a rate of $94 \mathrm{pmol} / \mathrm{h}$ into rats with hypothalamic anterolateral disconnection. After 5 days of treatment, the plasma corticosterone concentration was high in both the morning and evening, and did not differ from the evening concentration in the shamlesioned, non-CRF-treated rats. Although the neural connections were intact in our rats, the striking similarity of the diurnal corticosterone profile under chronic CRF stimulation in both experiments may indicate that the nocturnal activation of CRFneurons is functionally diminished in our rats. The most likely explanation is the negative feedback effect by the consistently increased morning plasma corticosterone. It is well established that corticosterone, even in the physiological range, exerts a negative feedback on ACTH secretion. Recently it has been reported that the feedback control of basal ACTH by corticosterone appears to be mediated primarily through the association of corticosterone with high-affinity, type I, corticosterone-preferring receptors (predominantly in the hippocampus and lateral septum, but not in the pituitary) and transsynaptical modulation of CRF-neuron activity during both the trough and the peak of the diurnal basal adrenocortical activity, and an apparent rightward shift in the feedback sensitivity at night may be a consequence of increased drive to the PVN from the SCN (Dallman et al., 1987b, Dallman et al., 1989). Thus, in unstimulated rats, the low morning plasma corticosterone seems to be a prerequisite for increased CRFneuron activity at night. This may be supported by the fact that in adrenalectomized rats, in which the plasma corticosterone is maintained at a certain level $(6-12 \mu \mathrm{g} / \mathrm{dl}$ but not below $4 \mu \mathrm{g} / \mathrm{dl}$ ) throughout a $24 \mathrm{~h}$ period by implantation of a corticosterone pellet, the augmented nocturnal surge of plasma ACTH disappears (Akana et al., 1986).

Although CRF receptors are widely distributed within the brain (River and Plotsky, 1986; Wynn et al., 1984), it is unlikely that the observed obliteration of corticosterone rhythm results from a centrallyadministered CRF effect on the rhythmgenerating system (the $\mathrm{SCN}$ ) per se since the circadian periodicity of locomotor activity was well maintained. It is also known that prolonged CRF administration leads to down-regulation and desensitization of the pituitary CRF receptors (Wynn et al., 1988). This, together with corticosterone feedback, may serve to keep ACTH secretion within a certain range, but is not likely to play an important role in the disruption of circadian ACTH-corticosterone rhythm.

Whatever the mechanism, the occupancy of the more ubiquitous type II receptors in the peripheral tissues remains low, as long as the plasma corticosterone concentration is maintained within the basal circadian range. In this way, the whole body is carefully protected from the profoundly deleterious effects of chronic glucocorticoid excess.

Recently, a role of CRF in the pathophysiology of primary depression has been proposed (Emeric-Sauval, 1986; Gold et al., 1988b; Taylor and Fishman, 1988), and an increased cerebrospinal fluid immunoreactive CRF concentration in depressed patients has been demonstrated (Nemeroff et al., 1984). The patients had a higher plasma cortisol level for $24 \mathrm{~h}$, the increase being more pronounced in the night but the circadian rhythm was preserved. (Rubin and Poland, 1982). This result resembles what 
we transiently observed in rats given a chronic icv infusion of CRF at a rate of $12 \mathrm{pmol} / \mathrm{h}$. At present it is not known whether more severe or late-phase disease leads to an arrhythmic cortisol profile, but even patients with a prolonged disease history usually remain free of apparent cushignoid physical stigmata.

\section{Acknowledgements}

This work was supported by a Grant-in-Aid for Scientific Research from the Ministry of Education, Science and Culture (63570530).

\section{Reference}

Akana, S. F., C. S. Cascio, J-Z. Du, N. Levin and M. F. Dallman (1986). Reset of feedback in the adrenocortical system: an apparent shift in sensitivity of adrenocorticotropin to inhibition by corticosterone between morning and evening. Endocrinology 119, 2325-2332.

Albe-Fessard, D., F. Stutinsky and S. Libouban (1966). Atlas stereotaxique du diencepale du rat blanc, Editions du centre national de la recherche scientifique.

Cascio, C. S., J. Shinsako and M. F. Dallman (1987). The suprachiasmatic nuclei stimulate evening ACTH secretion in the rat. Brain Res. 43, 173-178.

Cunningham, J. J., P. A. Meara, R. Y. Lee and H. H. Bode (1988). Chronic intracerebroventricular CRF infusion attenuates ACTH-corticosterone release. Am. J. Physiol. 255, E213E217.

Dallman, M. F., G. B. Makara, J. L. Roberts, N. Levin and M. Blum (1985). Corticotrope response to removal of releasing factors and corticosteroids in vivo. Endocrinology 117, 2190-2197.

Dallman, M. F., S. F. Akana, C. S. Cascio, D. N. Darlington, L. T. Jacobson and N. Levin (1987a). Regulation of ACTH secretion : variations on a theme of B. Recent Progr. Horm. Res. 43, 113-173.

Dallman, M. F., S. F. Akana, L. Jacobson, L. Levin, C. S. Cascio and J. Shinsako (1987b). Characterization of corticosterone feedback regulation of ACTH secretion. Ann. N. Y.
Acad. Sci. 512, 402-414.

Dallman, M. F., N. Levin, C. S. Cascio, S. F. Akana, L. Jacobson and R. W. Kuhn (1989). Pharmacological evidence that the inhibition of diurnal adrenocorticotropin secretion by corticosteroids is mediated via type 1 corticosterone-preferring receptors. Endocrinology 124, 2844-2850.

Emeric-Sauval, E. (1986). Corticotropin-releasing hormone (CRF) -a view. Psychoneuroendocrinol. 11, 277-294.

Gertz, B. J., L. N. Conteas, D. T. McComb, K. Kovacs, J. B. Tyrrel and M. F. Dallman (1987). Chronic administration of corticotropin-releasing factor increases pituitary corticotroph number. Endocrinology 120, 381388.

Gold, P. W., F. K. Goodwin and G. P. Chrousos (1988a). Clinical and biochemical manifestations of depression -relation to the neurobiology of stress- (second of two parts). New Engl. J. Med. 319, 413-420.

Gold, P. W., M. A. Kling, M. A. Demitrack, H. Whitfield, K. Kalogeras, D. L. Loriaux and G. P. Chrousos (1988b). Clinical studies with corticotropin releasing hormone; implication for hypothalamic-pituitary-adrenal dysfunction in depressed and related disorders. In : Current Topics in Neuroendocrinology (D. Ganten, D. Pfaff eds.), vol. 8, SpringerVerlag, Berlin Heidelberg New York, pp. 5577.

Honma, K. and T. Hiroshige (1978). Internal synchronization among several circadian rhythms in rats under constant light. Am. J. Physiol. 235, R243-R249.

Kalin, N. H., S. H. Shelton., G. W. Kraemer and W. T. McKinney (1983). Corticotropinreleasing factor administered intraventricularly to rhesus monkey Peptides 4, 217-220.

Lenz, H. J., A. Raedler, H. Greten and M. Brown (1987). CRF initiates biological actions within the brain that are observed in response to stress. Am. J. Physiol 252, R34-R39.

Miyabo, S., E. Ooya and S. Hayashi (1981). Effect of intrahypothalamic implantation of cortisone acetate on the onset of circadian corticosterone rhythm in neonatal female rats. Neuroendocrinology 33, 47-51.

Miyabo, S., I. Yamamura, E. Ooya, N. Aoyagi, Y. Horikawa and S. Hayashi (1985). Effects of neonatal treatment with monosodium glutamate on circadian locomotor rhythm in the 
rat. Brain Res. 339, 201-208.

Nemeroff, C. B., E. Widerlöv, G. Bissete, H. Walleus, I. Karlsson, K. Eklund, C. D. Kilts, P. T. Loosen and W. Vale (1984). Elevated concentrations of CSF corticotropin-releasing factor-like immunoreactivity in depressed patients. Science 226, 1342-1344.

Rivier, C. L. and W. Vale (1985). Effect of the long-term administration of corticotropinreleasing factor on the pituitary-adrenal and pituitary-gonadal axis in the male rat. $J$. Clin. Invest. 75, 689-694.

Rivier, C. L. and P. M. Plotsky (1986). Mediation by corticotropin-releasing factor (CRF) of adenohypophyseal hormone secretion. Ann. Rev. Physiol. 48, 475-494.

Rubin, R. T. and R. E. Poland (1982). The chronoendocrinology of endogenous depression. In : Neuroendocrine perspectives (E. E. Muller, M. Macleod eds.), vol. 1, Elsevier, Amsterdam. pp. 305-337.

Silberberg, S. and J. W. Funder (1988). Effect of 3 day infusion of ACTH or CRF on the pituitary-adrenal axis. Clin. Exp. Pharmacol. Physiol. 15, 15-21.

Sutton, R. E., G. F. Koob, M. LeMoa1, J. Rivier and W. Vale (1982). Corticotropin releasing factor produces behavioral activation in rats. Nature 297, 311-333.

Taylor, A. and L. M. Fishman (1988). Corticotropin-releasing hormone. New Engl. J. Med. 319, 213-222.

Wynn, P. C., R. L. Hauger, M. C. Holmes, M. A. Millan, K. J. Catt and G. Aguilera (1984). Brain and pituitary receptors for corticotropin releasing factor: localization and differential regulation after adrenalectomy. Peptides 5, 1077-1084.

Wynn, P. C., J. P. Harwood, K. J. Catt and G. Aguilera (1988). Corticotropin-releasing factor (CRF) induces desensitization of the rat pituitary CRF receptor-adenylate cyclase complex. Endocrinology 122, 315-356. 